\title{
The Use of Educational Exchange and International Education to Improve US-Sino Relationship
}

\author{
Eva Liu ${ }^{1}$ and Dr. Ethan Hutt ${ }^{2}$ \\ ${ }^{1}$ Pinewood School, Los Altos Hills, CA, USA \\ ${ }^{2}$ University of North Carolina, Chapel Hill, NC, USA \\ $\underline{\text { ABSTRACT }}$
}

As political scientist Graham Allison argues in his book, Destined for War, the United States and China "are currently on a collision course for war" (Allison, 2017, p. vii). Drawing on government reports and academic global education studies, this paper evaluates whether educational exchange and global education are plausible ways to de-escalate political tensions between the United States and China. This review indicates that studying abroad and educational exchange may de-escalate political tensions on a long-term horizon because of improved cultural understanding, foreign language acquisition, and students' potential of making an impact after gaining new perspectives. After comparing case studies of educational exchange programs, I concluded that a balanced, government-funded, long-term exchange program between high school students will be the most effective in de-escalating political tensions between the U.S. and China. High schoolers are the best candidates because they are more likely to accept new perspectives and take less time to acquire a foreign language. Cultural understanding and respect facilitate diplomatic relations, and high schoolers in exchange programs will provide that cultural understanding in the future. Many people may think that political, economic, and military compromises are the only ways to de-escalate political tensions, specifically between the U.S. and China. However, this paper proves that the impact of educational exchange should not be underestimated, and this proposed plan of using educational exchange programs to strengthen U.S.-Sino relations is an actionable step towards solutions both countries can take up now with few significant barriers to entry.

\section{Introduction}

As political scientist Graham Allison argues in his book, Destined for War, the United States and China "are currently on a collision course for war" (Allison, 2017, p. vii) because the two nations risk falling into the Thucydides' Trap. As Thucydides explained, war is inevitable when a rising power threatens to displace the ruling power. However, Allison argues that it is possible for China, the rising power, and the United States, the ruling power, to escape Thucydides' Trap. He believes that "cultural commonalities can help prevent conflict" (Allison, 2017, p. 200), and that is why the U.S. and Britain successfully avoided war in the early twentieth century, sharing a language and political culture.

Since the United States and China do not share that cultural bridge, educational exchange and global education can increase cultural understanding and facilitate cultural diplomacy, with the hope of de-escalating political tensions between the two nations. Compared to other strategies such as results-oriented engagement and cooperation at the alignment of interests (Allison, 2017, p. 214-240) to maintain peace with China, educational exchange and global education are familiar to both countries and this method of cultural diplomacy may be the most peaceful strategy.

In 2010, China and the United States worked together to expand a student exchange program, offering U.S. students 100,000 more places to study in China. This effort was led by the U.S. Secretary of State Hillary Clinton and State Councilor Yandong Liu and their talks regarding educational exchanges were the first meeting of Sino-U.S. high-level consultation on people-to-people exchanges. Both leaders expressed the benefits of these educational 
exchanges and how they could promote understanding and friendships among the future generations of both countries (Peck, 2014, p. 39-40).

Since 1978, when Deng Xiaoping began to send students and scholars abroad, about 800,000 Chinese students have studied abroad. In the past decade, China is the largest supplier of international students, and the liberalization of the education sector allowed more students outside of China to study in China. According to IEE, the number of Americans studying abroad in China increased by over 500\% in the past decade. Currently, China and the United States are mutually each other's biggest educational partners. Hundreds of American universities have established exchange programs with China, and more American students study in China than any other developing country. According to the Open Doors Report on International Education Exchange, as of 2015, eighty colleges and universities from 36 American states operate undergraduate degree programs in China while 30 offer graduate degrees. All Chinese provinces and autonomous regions have educational agreements with American universities, and all but Xinjiang, Tibet, and Qinghai have joint degree programs. NYU, Duke, and Kean have established comprehensive, joint venture, independent Chinese universities. However, in the Trump administration's fiscal year 2019 budget, proposed cuts in cultural and educational exchanges rose to around 75 percent, and his immigration policy will negatively affect educational exchange. Meanwhile, China is actively courting exchange students overseas from Latin America and the Caribbean and has committed to providing 6000 governmental scholarships to members of the Community of Latin America and the Caribbean States by 2019, according to Global Americans. Based on their research, the Global Americans co-chairs, Carolina Barco, Enrique García, Marc Grossman, and Arturo Sarukhan, recommended that the U.S. Congress should fully fund the State Department's Bureau of Educational and Cultural budget to place a greater emphasis on coordinating and working with alumni of student exchange programs to take advantage of research, exchange, and networking opportunities. They claim that exchange alumni are an untapped resource for strengthening cross-border relationships.

Even though the United States and China have already established educational partnerships, the impact of educational exchange and global education is beyond just the academic field, but also serves an important political purpose - cultural diplomacy. For the purpose of this paper, cultural diplomacy should be defined as the utilization of the exchange of ideas, values, and traditions of culture to strengthen relationships and promote national interests. Cultural diplomacy establishes trust and forms sustainable relationships and engages both the host community and visiting community in developing a solution. Furthermore, equal cross-cultural partnerships can challenge stereotypes about both countries (Entusi Interview, 2020). Many experts are looking for ways to maintain a peaceful relationship between the U.S. and China, but this paper can help the readers understand that an educational approach may be just as effective as political, economic, and military solutions.

The primary goal of this paper is to evaluate whether educational exchange and global education are plausible ways to de-escalate political tensions between the United States and China.

The major strands of work in this field show that studying abroad and educational exchange may de-escalate political tensions on a long-term horizon because of improved cultural understanding, foreign language acquisition, and students' potential of making an impact after gaining new perspectives. This educational approach will not solve the dilemma of U.S.-Sino relations immediately; rather, it will contribute to the diplomatic relations between the United States and China in the long term. Based on the study's results, a balanced, government-funded, long-term exchange program between high school students will be the most effective in de-escalating political tensions between the United States and China. High schoolers are the best candidates for cultural diplomacy because they are more likely to accept new perspectives and take less time to acquire a foreign language. Cultural understanding and respect facilitate diplomatic relations, and high schoolers in exchange programs will provide that cultural understanding in the future. 


\section{Methods}

I primarily conducted this research using the databases of Jstor and Google Scholars, and I used search terms such as "educational exchange," "international education," "foreign exchange", and "student exchange" to collect information. I mostly focused on case studies of study abroad and/or exchange programs between the United States and China because programs between the U.S. and another country may yield completely different results. To conclude the following results, I consulted 23 academic articles and case studies.

\section{Results}

Three main benefits of student exchange and global education programs consist of cultural diplomacy, foreign language acquisition, and change in students' beliefs and their potential to make an impact.

Beyond just education goals, the governments are interested in increasing educational exchanges and promoting international education because of the ultimate hope -- cultural diplomacy. While traditional diplomacy is practiced between high-level officials, cultural diplomacy is conducted during the interactions of people from different countries. Philip Coombs, former Assistant Secretary of State for Education and Cultural Affairs, framed educational exchange as the human side of American foreign policy because cultural relations focused on people, their ideas, their attitudes, and their knowledge (Coombs, 1964, p. 17). In practice, the U.S. government had previously used educational interactions to de-escalate political tensions; for example, the idea of accepting Chinese students to the states was designed to alleviate the negative impact of the Chinese exclusion policy in 1882. Cultural diplomacy is often more friendly and can be used to avoid direct political confrontations because participants in cultural diplomacy often have insights into foreign attitudes and cultures that high-level government officials do not. For example, during the Cold War, when fear of mutual destruction prevented military advances, educational exchanges gained the support of the government not for educational purposes, but rather to expand United States' cultural dominance. Scholar Liping $\mathrm{Bu}$ notes that the U.S. government took the lead in promoting educational and cultural exchanges in the Cold War, and "the programs began to be broadly integrated with political goals and foreign policy deliberations" (Bu, 1999, p. 414).

The goal of cultural diplomacy is to create honest mutual communication and understanding through educational exchange and international education because those students who study abroad either voluntarily or through an exchange program have the potential of becoming future political leaders of their home countries. This assumption gains support from an evaluation of the alumni from the Johns Hopkins exchange program in China. Many students took advantage of their cross-cultural interactions and became influential figures. For example, alumni Christi Caldwell was able to draw from her cross-cultural learning as an American assistant to the director of the Cultural Division of Taiwan's commercial office in the U.S., alumni James Hellert took the position of a vice-consul at the U.S. embassy in Beijing, and alumni Deming Chen became the mayor of Suzhou city in China (Wheeler, 2010, p. 84-85). Also, cultural diplomacy is effective because educational interactions are the strongest ties between the two peoples and the rise and fall of educational interactions inevitably have a lasting impact on the relationship between the two nations. From a historical perspective, educational exchanges between the U.S. and China underwent the largest expansion and an abrupt termination in the first half of the twentieth century. Undoubtedly, the educational exchange programs spurred Chinese modernization efforts and proved that the two peoples, with dramatically different ideologies and backgrounds, were able to share knowledge. However, the Chinese political regimes collapsed despite educational exchange programs because they rejected political or social reforms, alienating returned students. Meanwhile, Chinese students in Washington were angry that the U.S. government refused to revise hostile Chinese policies (Li, 2008, p. 176-201). Thus, for educational exchange to be enduring and efficient in the long run, both governments must focus on closer collaboration, stronger support, and deepened understanding of the importance of cultural diplomacy. 
Besides cultural diplomacy, another benefit of educational exchange and global education is foreign language acquisition. In most exchange and study abroad programs, culture and language courses are the norms. Consequently, students in their host countries have the opportunity to communicate with the locals in the foreign language, allowing them to be more observant of local cultures and the language itself. For example, Clemson University exchange program students reported that studying abroad helped them to recognize the importance of language in cultural contexts (Brown, 2009, p. 67). Kenneth Jarrett, a Johns Hopkins University exchange program alumnus, not only was able to substantially improve his language but gain insights from interacting with his Chinese roommate and local citizens (Wheeler, 2010, p. 83). Language acquisition indirectly contributes to political understanding and de-escalating political tensions because "political education is an implicit part of the study of a foreign language" (Starkey, 1999, p. 155).

Although cultural diplomacy and language acquisition are the most commonly acknowledged benefits of global education and foreign exchange programs, changes in student beliefs also play an important role in the mission of political de-escalation. American professors' teachings often expanded the intellectual horizons of the Chinese students, and the students were impressed that the American professors presented different sides of political issues. Specifically, one Chinese alumnus from the Johns Hopkins-Nanjing Center took classes about the U.S. legal system and the Constitution and recognized that the majority of Chinese university students are too influenced by mainstream media and fail to think independently (Wheeler, 2010, p.82). Similarly, another alumnus in the center learned why Chinese propaganda portrays America as a crazy country (Wheeler, 2010, p.82).

Despite all the benefits of foreign exchange and international education programs, there remain challenges to further promote these programs. To begin with, China is concerned about dominance and cultural dependence on the West. Economically, China is in a much stronger position to benefit from these cross-cultural interactions; however, the hazards of dependence on Western culture and education remain (Hayhoe, 1984, p. 40). The United States saw the benefits of returning Chinese students, believing that they can implement certain American ideals, especially freedom in education (Ma, 2003, p.56). However, that is exactly what the Chinese government wants to avoid. Returning students to China have had a hard time adjusting to their home environment because the Western attitudes they brought back were not always embraced in China, making it difficult for these students to find employment (Orleans, 1988, p. 57).

However, evaluating the impact of Chinese returning students from another perspective, these students also bring home knowledge and resources that can help China transition from a developing country to a developed country. Undoubtedly, those students bring back new ideas of culture and education, which can lead to new jobs and improved methods for improving the Chinese economy and global status.

\section{Discussion}

Even though study abroad programs and exchange programs both send students to a foreign country for educational purposes, the exchange programs are more beneficial for cultural understanding and political de-escalation. While study abroad programs are often hosted by colleges, exchange programs are organized by high schools, colleges, and the government. Thus, the study abroad programs often offer less oversight, especially if the program is facilitated by a third-party study abroad organization. On the other hand, there is much more involvement from the institutions in an exchange program. For example, the institution can help the student adapt to the new environment and accept the cultural shock. Another benefit of the exchange programs includes the opportunity to live with a host family, which allows the exchange students to understand the language and culture at a deeper level. Since many exchange programs are funded by the government, exchange students receive scholarships and grants, not only alleviating students' financial concerns but also boosting the quality of the program. Lastly, exchange programs ensure the flow of foreign students is a two-way exchange instead of a one-way infiltration. For example, the Fulbright Scholar Program was established in 1946 by Congress and is sponsored by the Bureau of Educational and Cultural Affairs of the U.S. Department of State. According to the SRI assessment of the impact of the Fulbright program, $90 \%$ of the visiting 
scholars watched or listened to local media, $80 \%$ participated in cultural events, and 49\% gave talks about their home country's culture (SRI International Center for Science, Technology and Economic Development [SRI], 2005, p. 5). Additionally, almost all visiting scholars gained knowledge about American culture and the political system. Remarkably, 66\% of scholars became more involved in activities that involve international cooperation (SRI, 2005, p. 7). Through the multiplier effect, the new knowledge about American culture and politics gained by the scholars is spread to their families and friends back home (SRI, 2005, p. 37).

As of program duration, the performance of long-term programs outdoes that of short-term programs. Longterm programs have a more lasting impact, given that students have more time to adapt to local cultures and overcome the language barrier. Long-term programs typically last more than a semester, and the students who spent the whole academic year abroad receive the most benefits (Dwyer, 2004, p. 151-163). In contrast, short-term programs may give students a false impression of the cultures of the host country. For example, in a five-week summer study abroad program in Spain, there were disparities in students' experiences in the program and perceptions of Spain according to race and gender (Talburt \& Stewart, 1999, p. 163-175).

College-level exchange programs achieve the most educationally, and the biggest beneficiaries are the students. College-level exchange programs often offer a variety of classes and more internship opportunities, and college students studying abroad have less of a leap than high school students and professionals. While college students live independently, high school students and professionals often live with their families. Therefore, moving to a foreign country for a year without their family tends to be more difficult for high school students and professionals. However, in many aspects, the college experience is similar between different countries, and colleges are too big for the foreign exchange students to always have interactions with local students.

Professional exchanges yield the most satisfactory results in terms of career and professional development. The Hubert H. Humphrey Fellowship Program is a one-year, non-degree professional development opportunity for rising leaders in public services fields. Fellows reported encouraging collaboration between countries that face similar challenges to find solutions together. Some Fellows served on international boards or committees, while others networked with counterparts in other countries to expand a particular project. Other Fellows, especially those who specialize in public policy, also work in high-profile international organizations, including the United Nations (UN), the World Health Organization (WHO), or the World Bank. The Hubert H. Humphrey Fellowship Program proved effective for cultural exchanges and understanding. More than $90 \%$ of surveyed foreign Fellows agreed that they had learned about U.S. society, culture, diversity, religion, government and policies, and the American people generally (General Dynamics Information Technology [GDIT], 2018). Their increased understanding of American society and people has enabled Fellows to serve as cultural interlocutors in their home countries. For example, Fellows shared that their English competency helped them to get jobs and others consulted them about U.S. policies and values. Approximately $85 \%$ of surveyed American stakeholders agreed that Fellows had effectively shared their cultures with their host communities, and at least $30 \%$ of surveyed Fellows have collaborated with U.S. contacts, whether it is joint training, conference, or project. Additionally, one in five surveyed Fellows have hosted a U.S. exchange program participant, and $85 \%$ said they would be interested if the opportunity is available (GDIT, 2018). However, professional exchanges face immense obstacles due to national security concerns and rising political tensions between the United States and China.

While college-level and professional exchanges have many advantages, high-school exchange programs should be prioritized for cultural and political purposes. High schoolers are more accepting to change, and since their values are still forming, their political beliefs are easier to shift. It is also easier for high schoolers to learn a new language, so the goal of language acquisition can be easily accomplished. Indeed, high school exchange programs proved highly successful. For example, the AFS intercultural programs include a high school exchange program in which students live with homestay families in the host country. According to AFS' short-term impact study in 2005 , measured with the Intercultural Developmental Inventory, students learned more about other cultures, became more fluent in a foreign language, increased their cultural competence, and developed expansive cultural networks. The long-term study results confirmed the increased levels of cultural understanding and foreign language fluency. 
For the purpose of this study, a one-year exchange program for high-schoolers should be prioritized and funded by the governments of the United States and China. The content and quality of study should be the focus rather than student participation rates. To maximize the level of language acquisition and cultural diplomacy, language and culture courses should be mandatory in the curriculum of the exchange program. Politics and history classes should be encouraged as well. Lastly, the government of both countries needs to work together to ensure the number of American and Chinese students is balanced.

\section{Conclusion}

Study abroad and exchange programs contribute to the de-escalation of political tensions because of cultural diplomacy, foreign language acquisition, and student potential to serve in the public service field. The research suggests that the government of the U.S. and China should co-fund balanced high-school exchange programs that last for an academic year. Many people may think that political, economic, and military compromises are the only way to deescalate political tensions, specifically between the United States and China. However, this paper proves that the impact of educational exchange and cultural diplomacy must not be underestimated, and this proposed plan of using educational exchange programs to de-escalate political tensions requires barely any sacrifice from both sides and does not cause ongoing controversy, unlike other proposals might.

\section{Limitations}

There is no universal way to evaluate the impact of educational exchange, and most of the data comes from student surveys and alumni interviews, which may not represent the bigger picture. There are relatively few studies that come from the perspective of a home country or a host country, and institutions are determining the success of study abroad and exchange programs by percent of students abroad, which only accounts for quantity but not quality. Even though there are more student and institutional participation in international education, core comparative education journals do not include much research. International education is seen as practitioner-oriented, so the research in this field does not focus on scholarly analysis (Streitwieser et al., 2012, p. 5).

\section{Acknowledgments}

This paper would not have been possible without the guidance and support of my counselor Tiffany, who encouraged me to pursue this project. She worked with me actively and always answered my questions and concerns when I ran into problems.

I am grateful to my advisor Dr. Ethan Hutt, whom I have had the pleasure to work with. He has provided me with professional guidance from the perspective of a college professor and helpful feedback on my writing.

I would like to thank my parents, whose love and support are with me throughout the process of completing this paper and in whatever I pursue.

\section{References}

Allison, G. T. (2017). Destined for war: Can America and China escape Thucydides' Trap? (pp. vii, 200, 214-240). Mariners Press.

Brown, J. (2009). Study abroad program evaluation: What can be learned from student satisfaction surveys? (pp. 67). [Master's thesis, Clemson University]. https://tigerprints.clemson.edu/all theses/747 
Bu, L. (1999). Educational exchange and cultural diplomacy in the Cold War. Journal of American Studies, 33(3), 414. https://doi.org/10.1017/S0021875899006167

Coombs, P. H. (1964). The fourth dimension of foreign policy: Educational and cultural affairs (pp. 17). New York: Harper and Row.

Dwyer, M. (2004). More is better: The impact of study abroad program duration. Frontiers: The Interdisciplinary Journal of Study Abroad, 10, 151-163.

Entusi Interview [Interview by R. Bokua \& R. Nowamaani]. (2020, June 25).

General Dynamics Information Technology. (2018). Hubert H. Humphrey Fellowship Program: Evaluation report. https://eca.state.gov/files/bureau/humphrey_report_october_2018_final_v2_508_compliant.pdf

Hayhoe, R. (1984). A comparative analysis of Chinese-Western academic exchange. Comparative Education, 20(1), 40. http://www.jstor.org/stable/3098651

Li, H. (2008). U.S.- China educational exchange: State, society, and intercultural relations, 1905-1950 (pp. 176201). New Brunswick: Rutgers University Press. https://www.jstor.org/stable/j.ctt5hj1g5

Ma, J. T. (2003). From studying in America to staying in America. Chinese Studies in History, 56.

Orleans, L. A. (1988). Chinese students in America: Policies, issues, and numbers (pp. 57). Washington, DC: The National Academies Press. https://doi.org/10.17226/743

Peck, K. (2014). The impact of academic exchange between China and the U.S., 1979-2010. Psi Sigma Siren, 8(1), 39-40. https://digitalscholarship.unlv.edu/psi sigma siren/vol8/iss1/4

SRI International Center for Science, Technology and Economic Development. (2005). Outcome assessment of the visiting Fulbright Scholar Program (pp. 5, 7, 37). https://files.eric.ed.gov/fulltext/ED495810.pdf

Starkey, H. (1999). Foreign language teaching to adults: implicit and explicit political education (pp. 155). Oxford Review of Education. http://dx.doi.org/10.1080/030549899104189

Streitwieser, B. T., Le, E., \& Rust, V. (2012). Research on study abroad, mobility, and student exchange in comparative education scholarship. Research in Comparative and International Education, 7(1), 5. http://dx.doi.org/10.2304/rcie.2012.7.1.5

Talburt, S., \& Stewart, M. (1999). What's the subject of study abroad?: Race, gender, and "living culture." The Modern Language Journal, 163-175. https://www.jstor.org/stable/330333

Wheeler, N. (2010). Educational exchange in Post-Mao U.S.-China relations: The Hopkins-Nanjing Center. The Journal of American-East Asian Relations, 17(1), 82-85. http://www.jstor.org/stable/23613332 